\title{
Thermophysiological Comfort Analysis of Aerogel Nanoparticle Incorporated Fabric for Fire Fighter's Protective Clothing
}

\author{
Abu Shaid ${ }^{1, *}$, Mac Furgusson², Lijing Wang ${ }^{2}$ \\ ${ }^{1}$ Department of Textile Engineering, Dhaka University of Engineering \& Technology; Bangladesh \\ ${ }^{2}$ School of Fashion and Textiles, RMIT University, Australia
}

Copyright (C) 2014 Horizon Research Publishing All rights reserved.

\begin{abstract}
The paper discusses the thermophysiological comfort of a newly developed fabric potentially for firefighter's protective clothing. The fabrics were developed by incorporating super hydrophobic silica aerogel nanoparticles in 65/35 wool-Aramid blended fabric. Then the theromophysiological comfort was analyzed by determining air, moisture and heat transfer performance. It has been found that only $2 \%$ coating of aerogel nanoparticle increases thermal resistance by up to $68.64 \%$ and can reduce air permeability by up to $45.46 \%$ whereas $4 \%$ aerogel coating can reduce $61.76 \%$ air permeability. Moisture management properties of the aerogel coated fabric have also been investigated and discussed in details. In brief, it can be said that the thickener that was used for the coating, has a positive impact on moisture transportation and overall moisture management property of the fabric. Again aerogel coated next-to-skin layer and aerogel coated outer layer acted differently on the same fabric. It was observed that, the coated fabric acts as more likely as a moisture management fabric when the coating was applied on next-to-skin surface.
\end{abstract}

Keywords Thermophysiology, Comfort, Aerogel Nanoparticle, Coating, Moisture Management

\section{Introduction}

Clothing is the primary protection for mankind against extreme cold or hot environmental situations. Sometime protection against fire and heat becomes the first priority in a specific field of application. Firefighting is such a field where flame protection and thermal insulation are needed. The paper investigates the applicability of aerogel incorporated fabric for firefighter's garments considering the wearer comfort in respect of moisture, air and heat transfer properties.

Aerogel was first prepared by Samuel Stephens Kistler [1, $2]$ in 1931. It is a highly porous [3, 4], almost transparent [5] and extremely light weight material [6] that can resist flame and act as a super heat insulator [7-10]. The bulk density of aerogel is as low as $0.1 \mathrm{~g} / \mathrm{cm}^{3}$ [8]. One of the most significant properties of aerogel is its impressive flame proofing and thermal insulation [11]. Its thermal conductivity can be as low as $0.02 \mathrm{~W} / \mathrm{mK}[7,8]$. Aerogel can nullify all the three methods of heat transfer. Convective heat transfer is prevented as aerogel structure does not permit air circulation. Conductive transfer of heat is prohibited as most of the aerogel structure is gaseous and gas has very low heat conductivity [12]. The gaseous structure of aerogel is derived from its porous construction $[9,10]$. Aerogel can also absorb the infrared radiation that transfers heat [13-15]. Thus aerogels can act as an extraordinary thermal insulator. However aerogel has few crucial drawbacks that hinder its way in apparel application. Primary aerogels were brittle and were produced through a costly, time consuming and complex process [16]. Recent advancement of aerogel science has made it possible to produce flexible aerogel in simpler ways [12, 17-19]. All these indicate the bright prospect of aerogels in fire-fighting garments for thermal insulation and protection.

When designing any fabric for Firefighter's protective clothing, human comfort is a vital factor besides protection performance. The human body can control its internal temperature at a certain level when external or internal conditions change. Specific central and peripheral nervous system continuously identify the temperature instability in the body and always try to keep a balance through its own biological action [20]. Physiologically, a human being is regarded as feeling comfortable when skin temperature is between $33^{\circ} \mathrm{C}$ and $35^{\circ} \mathrm{C}$ and there is no deposition of liquid sweat on the skin [21]. The comfort can be thermal, physical, sensational or thermophysiological. Thermophysiological wear comfort refers to the heat and moisture transport properties of clothing and the way that the clothing maintains the heat balance of the body [22, 23]. Thermophysiology is one of key factors that induce stress. It has been found that the thermal transmission through 
textiles increases with their moisture content and air velocity [21, 24]. Increased wind velocity can reduce the thermal insulation of a fabric compared with its insulation in still air [21]. Hence heat, air and moisture transport properties must all be considered to predict wearer comfort $[25,26]$. This paper investigates the air, moisture and heat transfer properties of superhydrophobic aerogel nanoparticle coated fabrics as to analyze the thermophysiological comfort of the wearer.

\section{Materials and Methods}

$65 / 35$ wool/Aramid blended fabric of around $230 \mathrm{~g} / \mathrm{m}^{2}$ was coated with different percentages of "NANOGEL" (superhydrophobic aerogel nanoparticle from Cabot) by using an acrylic binder. $2 \%, 4 \%$ and $8 \%$ aerogel coated fabric were produced where the average viscosity of the coating paste was 20,000 to 30,000 centipoise. Coated fabrics were cured at $105^{\circ} \mathrm{C}$ for $10 \mathrm{~min}$. Then the thermophysiological properties were analyzed.

Physical fabric parameters were investigated in terms of thickness, weight $\left(\mathrm{g} / \mathrm{m}^{2}\right)$ and fabric construction (Ends and Picks per inch). Fabric thickness was measured using a laboratory thickness gauge according to the test method "AS 2001.2.15-1989". Fabric's mass per unit area was measured according to "AS 2001.2.13-1987" test method and fabric construction was determined by using counting glass and needle. A MOTIC microscope was used with MOTIC image software to evaluate the surface properties of the coated fabric.

Moisture management properties were tested and analyzed according to AATCC 195-2010 test method by using a SDL Moisture Management Tester (Figure 1). A series of indexes were defined and calculated to characterize liquid moisture management performance, including the overall 'moisture management capacity' OMMC [27] as defined in Equation I [28]. A larger OMMC means a better overall moisture management ability of the fabric tested.

$$
\mathrm{OMMC}=0.25 \mathrm{MAR}_{\mathrm{b}}+0.5 \mathrm{OWTC}+0.25 \mathrm{SS}_{\mathrm{b}}(\mathrm{I})
$$

Where, $\mathrm{MAR}_{\mathrm{b}}$ is the Maximum Absorption Rate of the fabric's bottom surface; OWTC is One Way Transport Capacity; and $\mathrm{SS}_{\mathrm{b}}$ is the Spreading Speed of the fabric's bottom surface.

Thermal resistance of the fabric was measured according to ISO 11092: 1993 test procedure by using a sweating guarded hot plate, referred to as the "skin model"(Figure 1). This instrument is intended to simulate the heat and mass transfer processes which occur next to the surface of the skin [29, 30]. Here, the thermal resistance (Rct) is the temperature difference between the two faces of a material divided by the resultant heat flux per unit area in the direction of the gradient. Thermal resistance, expressed in square meters Kelvin per watt, is a quantity specific to textile materials or composites. Rct determines the dry heat flux across a given area in response to a steady applied temperature gradient. The specimen to be tested was placed on an electrically heated plate with conditioned air ducted to flow across and parallel to its upper surface as specified in ISO 11092. For the determination of thermal resistance, the heat flux through the test specimen was measured after steady-state conditions have been reached. Standard machine settings for thermal resistance test were: Measurement unit temperature: $35^{\circ} \mathrm{C}$; Thermal guards temperature: $35^{\circ} \mathrm{C}$; Air temperature: $20^{\circ} \mathrm{C}$; Air speed: $1 \mathrm{~m} / \mathrm{sec}$; Relative humidity: $65 \%$.

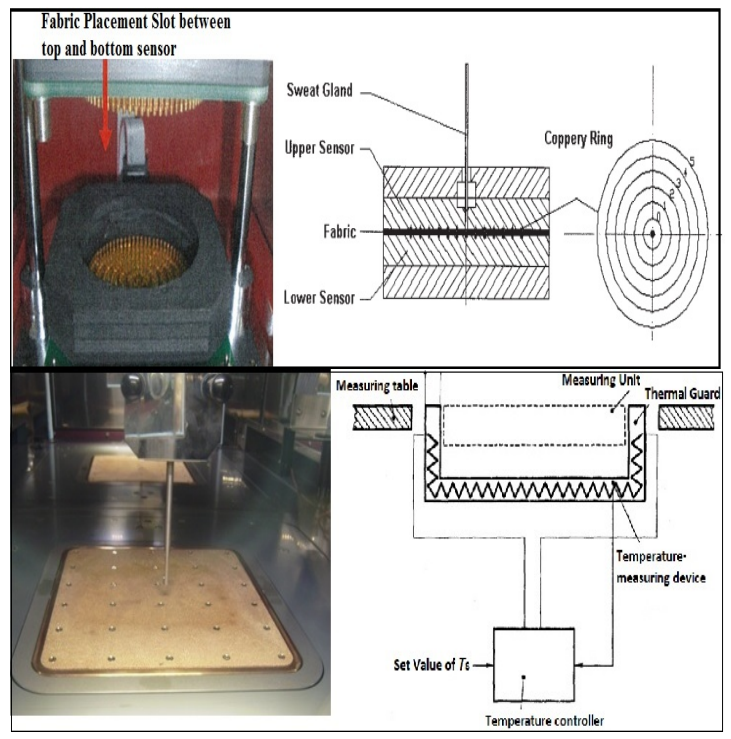

Figure 1. Measuring unit of MMT (Top) and Sweating Guarded Hotplate (Bottom)

Air permeability of the coated fabric was measured according to EN ISO 9237:1995 test method by using SDL Air Permeability Tester. It is calculated using the Equation II as follows-

Air permeability, $\mathrm{R}=(\mathrm{qv} / \mathrm{A}) \times 167 \mathrm{~mL} / \mathrm{cm}^{2} / \mathrm{s}$ at $100 \mathrm{pa}$ (II)

Where, $\mathrm{qv}=$ the arithmetic mean flow rate of air from 5 tests, in cubic decimeters per minute (liters per minute).

$\mathrm{A}=$ is the area of fabric under test, in square centimeters; In our case, $\mathrm{A}=20 \mathrm{~cm}^{2}$.

$167=$ is the conversion factor from cubic decimeters (or liters) per minute per square centimeter to millimeters per second.

\section{Results}

$2 \%, 4 \%$ and $8 \%$ aerogel coated fabrics were developed and Figure 2 shows the fabric images. For the ease of identification, different fabric types used for the test purpose were coded as follows:

- A1: $2 \%$ aerogel, coated on the outer surface of the fabric;

- $\mathrm{A} 1_{\text {opst }}$ : $2 \%$ aerogel, coated on the 'next-to-skin' surface of the fabric; 
- A4: 4\% aerogel, coated on the outer surface of the fabric;

- A8: $8 \%$ aerogel, coated on the outer surface of the fabric.

- B: fabric coated with paste containing everything but aerogel;

- C: uncoated fabric;

- D: Gore-tex ${ }^{\circledR}$ Airlock fabric.

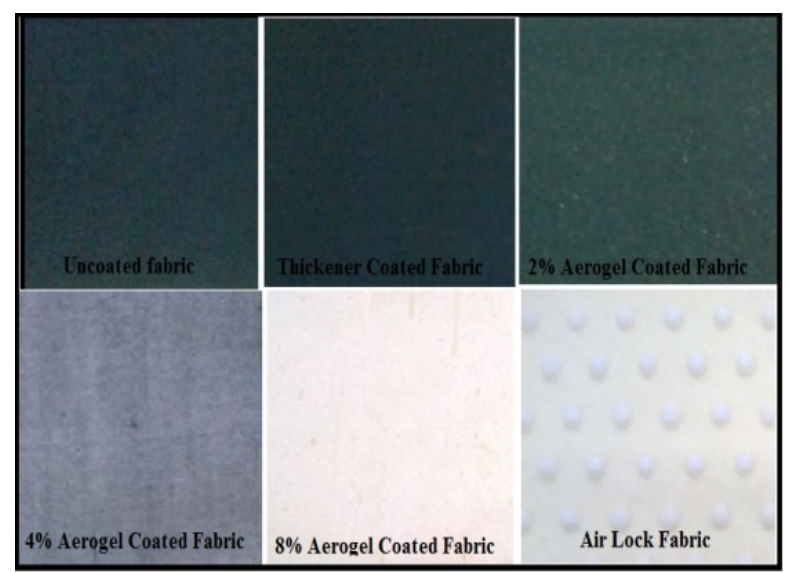

Figure 2. Different types of coated and uncoated fabrics.

All the test results are presented in Tables 1 and 2, and Figures 4 and 5 .

After coating, along with measuring physical parameters like weight and thickness, fabric's microscopic images were also analyzed. The results are shown in Figure 3.
Table 1. Test result summary.

\begin{tabular}{|c|c|c|c|c|}
\hline Fabrics & $\begin{array}{c}\text { Thickness } \\
(\mathrm{mm})\end{array}$ & $\begin{array}{c}\text { Weight } \\
(\mathrm{g} / \mathrm{m} 2)\end{array}$ & $\begin{array}{c}\text { Air } \\
\text { permeability } \\
\left(\mathrm{mL} / \mathrm{cm}^{2} / \mathrm{s}\right)\end{array}$ & $\begin{array}{c}\text { Thermal } \\
\text { Resistance } \\
(\mathrm{m} 2 \cdot \mathrm{k} / \mathrm{w})\end{array}$ \\
\hline A1 & 0.47 & 236 & 64.3 & 0.0199 \\
\hline A1opst & 0.47 & 236 & 64.3 & $\mathrm{X}$ \\
\hline A4 & 0.48 & 242 & 45.1 & $\mathrm{X}$ \\
\hline A8 & 0.68 & $\mathrm{X}$ & 10.2 & $\mathrm{X}$ \\
\hline B & 0.47 & 235 & 111.6 & 0.0118 \\
\hline C & 0.45 & 221 & 117.9 & $\mathrm{X}$ \\
\hline $\mathrm{D}$ & 0.69 & $\mathrm{X}$ & 10.2 & $\mathrm{X}$ \\
\hline
\end{tabular}

Note: $\mathrm{X}=$ Not tested.

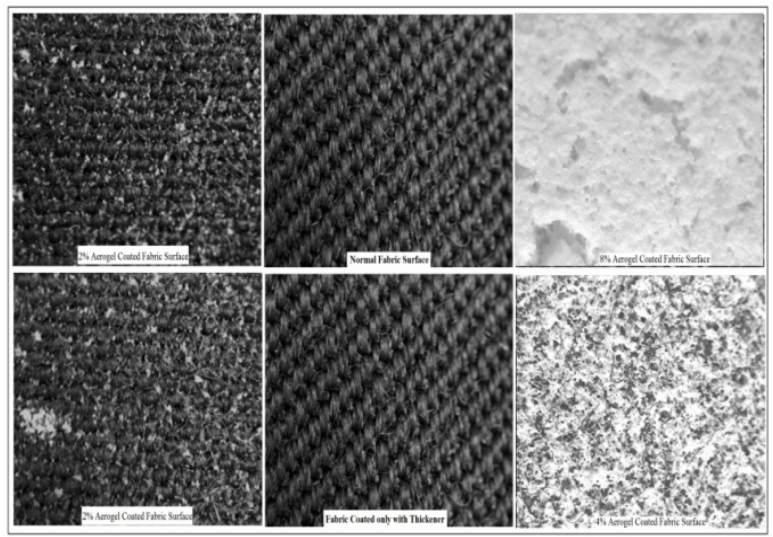

Figure 3. Microscopic view of few selected fabric samples-: fabric type A1,C, A8 (from top left) and A1, B, A4 (from bottom left)

Table 2. Summary of the Moisture Management Properties.

\begin{tabular}{|c|c|c|c|c|c|c|c|c|c|c|}
\hline \multirow[t]{2}{*}{$\begin{array}{l}\text { Fabric } \\
\text { types }\end{array}$} & \multicolumn{2}{|c|}{$\begin{array}{l}\text { Wetting time } \\
\text { (sec) }\end{array}$} & \multicolumn{2}{|c|}{$\begin{array}{ll}\begin{array}{l}\text { Absorption } \\
(\% / s e c)\end{array} & \text { rate } \\
(\% / \mathrm{s}\end{array}$} & \multicolumn{2}{|c|}{$\begin{array}{l}\text { Max wetted } \\
\text { radius }(\mathrm{mm})\end{array}$} & \multicolumn{2}{|c|}{$\begin{array}{l}\text { Spreading speed } \\
(\mathrm{mm} / \mathrm{s})\end{array}$} & \multirow{2}{*}{$\begin{array}{l}\text { One way } \\
\text { transport } \\
\text { capability } \\
\text { (OWTC) }\end{array}$} & \multirow{2}{*}{$\begin{array}{l}\text { Overall } \\
\text { Moisture } \\
\text { Management } \\
\text { Capacity } \\
\text { (OMMC) }\end{array}$} \\
\hline & $\begin{array}{l}\text { Top, } \\
W T_{t}\end{array}$ & $\begin{array}{l}\text { Bottom, } \\
\text { WT }_{b}\end{array}$ & $\begin{array}{l}\text { Top, } \\
\text { MAR }_{t}\end{array}$ & $\begin{array}{l}\text { Bottom, } \\
\text { MAR }_{\mathrm{b}}\end{array}$ & $\begin{array}{l}\text { Top, } \\
\text { MWR }_{t}\end{array}$ & $\begin{array}{l}\text { Bottom, } \\
\text { MWR }_{\mathrm{b}}\end{array}$ & $\begin{array}{l}\text { Top, } \\
\text { SS }_{t}\end{array}$ & $\begin{array}{l}\text { Bottom } \\
\text { SS }_{\mathrm{b}}\end{array}$ & & \\
\hline A1 & 5.875 & $\begin{array}{l}119.953 \\
\text { (no } \\
\text { wetting) }\end{array}$ & 58.6642 & 0 & 5 & 0 & 0.829 & 0 & -956.777 & 0 \\
\hline B & 7.078 & 57.641 & 350.6604 & 29.117 & 5 & 5 & 0.6912 & 0.0865 & -251.516 & 0.0531 \\
\hline C & 6.281 & \begin{tabular}{|l|}
119.953 \\
(no \\
wetting)
\end{tabular} & 332.7334 & 0 & 5 & 0 & 0.7768 & 0 & -782.249 & 0 \\
\hline A1 $1_{\text {opst }}$ & 7.156 & 84.437 & 380.7519 & 4.1526 & 5 & 5 & 0.6938 & 0.0591 & \begin{tabular}{|l|}
-788.935 \\
\end{tabular} & 0 \\
\hline D & 7.191 & 119.953 & 363.3929 & 0 & 5 & 0 & 0.6923 & 0 & -855.3841 & 0 \\
\hline
\end{tabular}




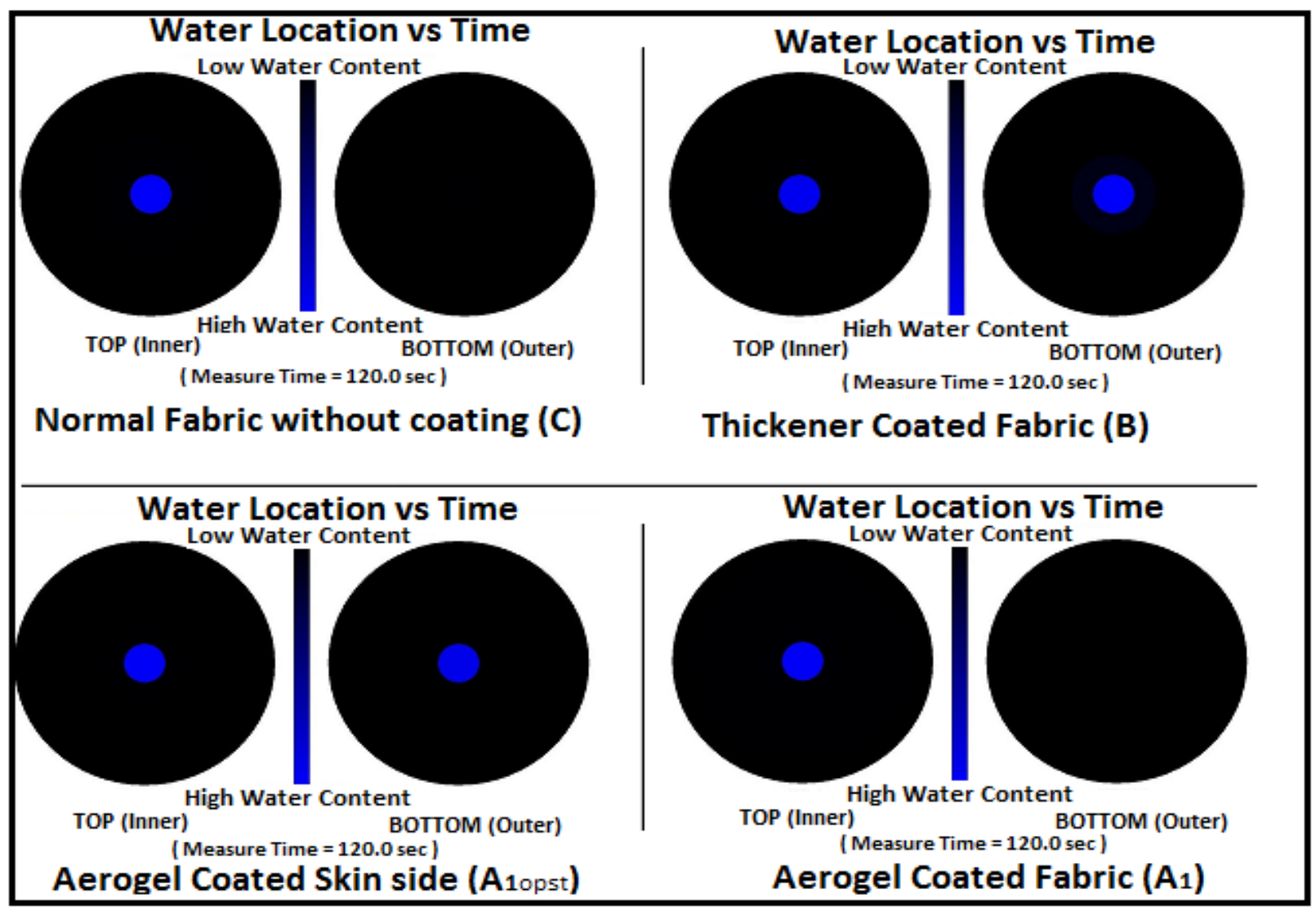

Figure 4. Maximum wetted radius at top and bottom surface.

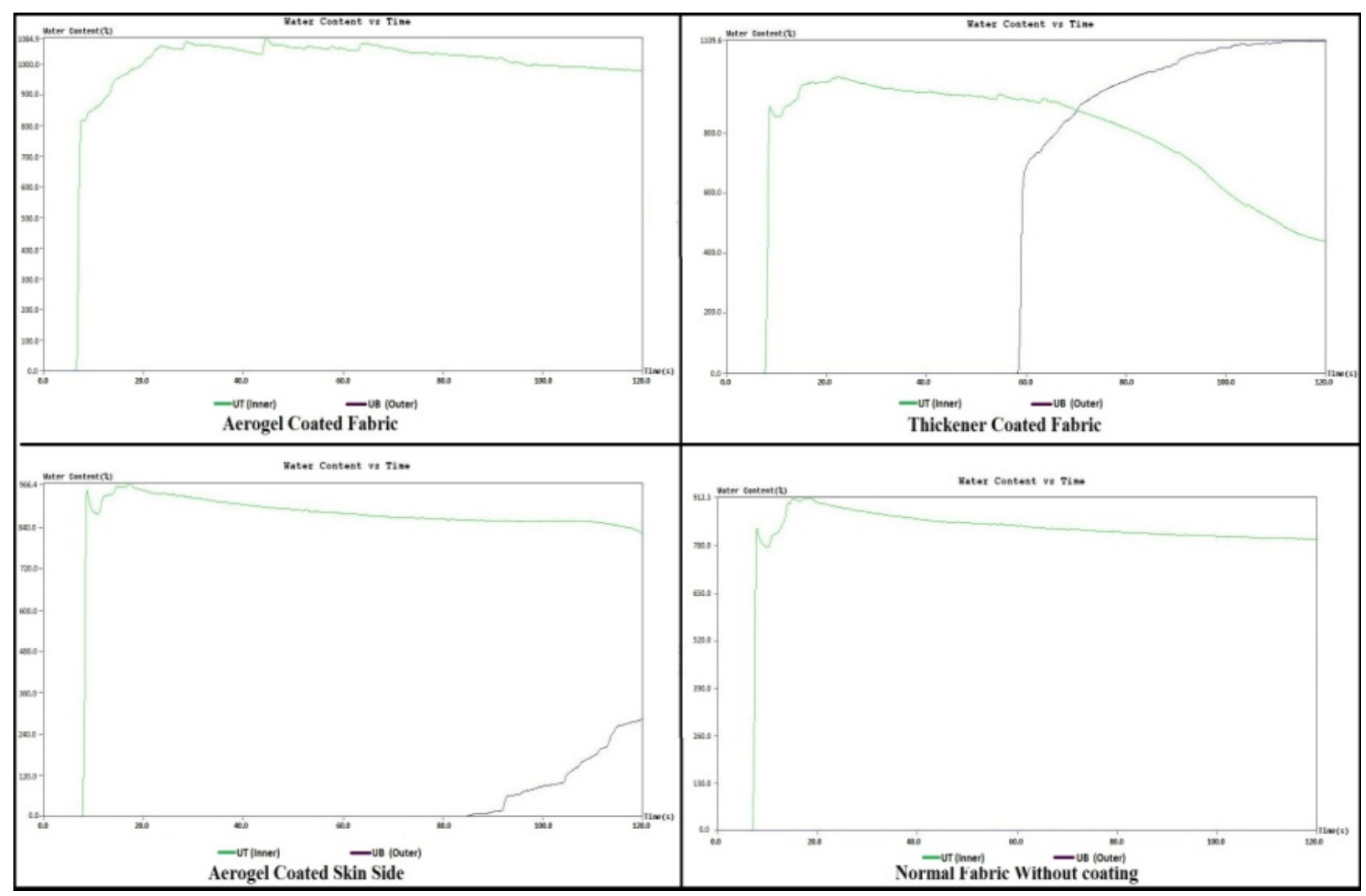

Figure 5. Water content vs Time 


\section{Discussion}

From Figure 3, it has been found that coating of 2\% aerogel paste, the aerogel particles did not significantly cover the surface whereas $4 \%$ coating showing partial covering. For $8 \%$ coating, the aerogel powder completely covered the fabric surface.

To check the physical changes, thickness and mass per unit area of the fabric were analyzed (Table 1). Due to aerogel coating, around 4 to $6 \%$ increment of thickness and 6 to $9 \%$ increment of fabric weight was observed. Thickness increases the resistance to the transfer of heat and moisture. Previous research showed that when two fabrics possess equal thickness, the lower-density fabric has the greater thermal insulation [21]. In our case, coating resulted in a gradual increment of insulation as shown in Table 1. Furthermore, three specific thermophysiological properties are discussed below on the basis of test results given above.

\subsection{Air Permeability}

Air permeability, being a biophysical feature of textiles, determines the ability of air to flow through the fabric. It can be greatly affected by the finishing treatment [31]. As our present fabric is a coated fabric, hence air permeability is a decisive factor. From the test data in Table 1, it is clear that the aerogel coating resists the airflow. An uncoated fabric allowed air permeability up to 117.9 $\mathrm{mL} / \mathrm{cm}^{2} / \mathrm{s}$ whereas $2 \%$ coating with aerogel reduced air permeability by up to $45.5 \%\left(64.3 \mathrm{~mL} / \mathrm{cm}^{2} / \mathrm{s}\right)$. Again when the amount of aerogel is increased in the coating film, it leads gradually greater resistance to airflow. The research has found that $8 \%$ aerogel coating on fabric surface lowered the air permeability by up to $91.36 \%$ which indicates low air permeability as low as the goretex airlock fabric (Table 1). This suggests that the $8 \%$ aerogel coated fabric may be served as an alternative fabric.

\subsection{Moisture Management}

Wearer's perception of moisture comfort sensations and clothing comfort is directly related to the absorption of moisture or body sweat by the garment in the garment-skin microclimate, and its transportation through and across the fabric where it is evaporated [28, 32-35]. Determination of moisture management property is unlike to the determination of fabric's simple absorbency and wicking properties (AATCC 2000 Test Method 79, BS 3424: Part 18: 1986) or the liquid strike-through time of nonwovens (ISO 9073-8). Moisture Management Test is used to analyze the behavior of dynamic liquid transfer in clothing materials by measuring of electrical resistance which is directly related to the water content in the fabric $[36,37]$.

The uncoated fabric, which was chosen for the study, has found as a water proof fabric according to the MMT analysis (Table 2, and Figures 4 and 5). The result shows that the water does not penetrate through the skin layer to the outer surface. After coating the outer surface of the fabric with aerogel, no significant difference in moisture management properties was observed, as the water actually did not go through from the skin layer to the outer aerogel layer. However, when the aerogel coated layer has been used as next to skin layer $\left(\mathrm{A} 1_{\text {opst }}\right)$, significant and important moisture management properties were observed as follows:

Firstly, aerogel coated next-to-skin surface can absorb moisture and release it to the environment easily. In uncoated state, there was no wetting on the bottom surface during the total experiment time of $120 \mathrm{sec}$ (Figure 5). When aerogel coated surface used as skin side, it has been found that the bottom surface get wetted in $84 \mathrm{sec}$ (Figure 5 ), which is a sign of significant improvement for moisture transportation from the skin side to outer atmosphere.

Secondly, moisture absorption rate has increased. In normal uncoated state, the moisture absorption rate found $332 \%$ and $0 \%$ at the top and bottom surface respectively whereas after using aerogel coating at the skin-side, the moisture absorption rate was $380 \%$ and $4.15 \%$ at the top and bottom surface respectively (Table 2). This improvement indicates that water vapor can be absorbed in greater amount and at both surface after coating with aerogel nanoparticle.

Thirdly, the drying speed of a fabric depends on maximum wetted radius and spreading speed. The difference between a slow and rapid-drying fabric is in their water spreading speed and water spreading area. On a rapid-drying fabric, water spreads quickly and creates large spreading area whereas on a slow-drying fabric, water spreads slowly and forms comparatively smaller spreading area. The 'maximum wetted radius' on both surfaces was $5 \mathrm{~mm}$ when aerogel coating was used on the skin-side (Figure 3). However, when the outer surface was coated, no water went through and there were no wetted radius on the bottom surface (outer of the garment) (Figure 3). This change is a sign of improvement in fabric drying speed. Therefore, it can be said that aerogel coated on the skin-sided surface will dry more quickly than the garment where aerogel is coated on the outer surface.

The fabric with thickener coating only has the highest Overall Moisture Management Capacity (Table 2). This suggests that the presence of thickener helps to attract water and helps to overcome hydrophobicity of aerogel coated fabrics. Therefore, from the aerogel application perspective, it can be summarize that if aerogel is coated on the skin-side of the garment then it may feel more comfortable than the garment coated on the outer surface. When the moisture is absorbed at the skin surface but is not absorbed by the outer surface, then the body will feel wetted and uncomfortable due to the presence of unwanted wet feeling on skin. For the fabric $\mathrm{A} 1, \mathrm{C}$ and $\mathrm{D}$, very low wetted radius and spreading rates $\left(\mathrm{MWR}_{\mathrm{b}}=0 \mathrm{~mm}\right.$ and $\mathrm{SS}_{\mathrm{b}}=0 \mathrm{~mm} / \mathrm{s}$, Table 2) on the bottom surface along with negative one-way transport capacity (OWTC) indicates that the liquid (sweat) cannot diffuse easily from the next-to-skin surface to the opposite side and will accumulate on the skin-surface of the 
fabric. After coating the skin side with aerogel, the skin side absorbs more moisture and outer surfaces also start absorbing, i.e., started removing moisture from the skin surface. Thus the fabric will provide better comfort properties.

\subsection{Thermal Resistance}

From the test results in Table 1 it is clear that the aerogel particles on the fabric surface increase the thermal resistance of the fabric. The thickener coated fabric has showed thermal resistance of $0.0118 \mathrm{~m}^{2} \mathrm{~K} / \mathrm{W}$ whereas the aerogel coated fabric (A1) has showed thermal resistance of $0.0199 \mathrm{~m}^{2} \mathrm{~K} / \mathrm{W}$ (Table-1). In other word, $2 \%$ coating of aerogel provided $68.64 \%$ increase in thermal resistance.

\section{Conclusion}

The paper investigated the possibility of Aerogel incorporation in firefighter's protective gear in respect of thermophysiological comfort of the wearer. Here thermophysiology had been addressed in terms of air, moisture and heat transfer properties of Aerogel coated fabric. All these three parameters are discussed accordingly. In brief, following findings are derived from the test results:

a) The Aerogel coated fabric has an excellent air resistance.

b) Suitable selection of coating thickener can reduce the hydrophobic characteristic of aerogel and the base fabric; thus enhancing moisture management properties.

c) The Aerogel coated fabric provides better thermal insulation properties.

Aerogel itself is thermally insulative and the present research has identified that it can also resist the airflow significantly. The combination of these two shows a way to manufacture textiles for apparel which will provide thermally superior insulation for many application fields for extreme hot or cold weather condition.

Beside the inspirational findings, due to limited time boundary the project suffers form few unavoidable limitations such as the thermal resistance were not measured for all types of fabric samples that were developed. Again, the moisture management tests carried out requires more detail investigation in border range for different types of coating with different Aerogel and thickener compositions on various fabric structures. However, with positive research findings, the paper provides an overall guideline of further investigation on Aerogel incorporation in protective garments.

\section{Acknowledgements}

The authors would like to thank Ms Nazia Nawaz for her cordial advice during testing with the skin model, Ms
Trudie Orchard and Dr. Olga Troynikov for their support and encouragement during the course of this investigative project. Author is also grateful to the faculty members and technical stuffs of school of fashion and textile, RMIT University, Australia for providing testing and training facilities.

\section{REFERENCES}

[1] Kistler, S., Coherent Expanded Aerogels and Jellies. Nature, 1931. 127(3211): p. 741.

[2] Kistler, S. and A. Caldwell, Thermal conductivity of silica aerogel. Industrial \& Engineering Chemistry, 1934. 26(6): p. 658-662.

[3] Jin, H., et al., Nanofibrillar cellulose aerogels. Colloids and Surfaces A: Physicochemical and Engineering Aspects, 2004. 240(1): p. 63-67.

[4] Abramian, L. and H. El-Rassy, Adsorption kinetics and thermodynamics of azo-dye Orange II onto highly porous titania aerogel. Chemical Engineering Journal, 2009. 150(2): p. $403-410$.

[5] Tabata, M., et al., Development of transparent silica aerogel over a wide range of densities. Nuclear Instruments and Methods in Physics Research Section A: Accelerators, Spectrometers, Detectors and Associated Equipment, 2010. 623(1): p. 339-341.

[6] Liebner, F., et al., Cellulosic aerogels as ultra-lightweight materials. Part 2: Synthesis and properties 2nd ICC 2007, Tokyo, Japan, October 25-29, 2007. Holzforschung, 2009. 63(1): p. 3-11.

[7] Stark, R.W., et al., Determination of elastic properties of single aerogel powder particles with the AFM. Ultramicroscopy, 1998. 75(3): p. 161-169.

[8] Bhagat, S.D., et al., Superhydrophobic silica aerogel powders with simultaneous surface modification, solvent exchange and sodium ion removal from hydrogels. Microporous and Mesoporous Materials, 2008. 112(1-3): p. 504-509.

[9] Hostler, S., et al., Thermal conductivity of a clay-based aerogel. International Journal of Heat and Mass Transfer, 2009. 52(3): p. 665-669.

[10] Baetens, R., B.P. Jelle, and A. Gustavsen, Aerogel insulation for building applications: A state-of-the-art review. Energy and Buildings, 2011. 43(4): p. 761-769.

[11] REN, Q., L. LIN, and H. ZHENG, Research of fireproof and insulation composite fabric by use of silica aerogels. Shanghai Textile Science \& Technology, 2011. 12: p. 023.

[12] $\mathrm{Xu}, \mathrm{B}$., et al., An improved method for preparing monolithic aerogels based on methyltrimethoxysilane at ambient pressure Part I: Process development and macrostructures of the aerogels. Microporous and Mesoporous Materials, 2012. 148(1): p. 145-151.

[13] Fricke, J., Aerogels. 1986: Springer-Verlag.

[14] Lee, D., et al., Thermal characterization of carbon-opacified silica aerogels. Journal of Non-Crystalline Solids, 1995. 
186(0): p. 285-290.

[15] Fricke, J., et al., Thermal properties of silica aerogels. Le Journal de Physique Colloques, 1989. 50(C4): p. 4-4.

[16] Henning, S. and L. Svensson, Production of Silica Aerogel. Physica Scripta, 1981. 23(4B): p. 697.

[17] Venkateswara Rao, A., et al., Synthesis of flexible silica aerogels using methyltrimethoxysilane (MTMS) precursor. Journal of Colloid and Interface Science, 2006. 300(1): p. 279-285.

[18] Wei, T.-Y., et al., Preparation of Monolithic Silica Aerogel of Low Thermal Conductivity by Ambient Pressure Drying. Journal of the American Ceramic Society, 2007. 90(7): p. 2003-2007.

[19] Xu, B., et al., An improved method for preparing monolithic aerogels based on methyltrimethoxysilane at ambient pressure Part II: Microstructure and performance of the aerogels. Microporous and Mesoporous Materials, 2012. 148(1): p. 152-158.

[20] Li, Y. and A.S.W. Wong, Physiology of thermal comfort. 2006, Cambridge: The Textile Institue, CRC Press, Woodhead Publishing Limited.

[21] Ukponmwan, J.O., The Thermal-insulation Properties of Fabrics. Textile Progress, 1993. 24(4): p. 1-54.

[22] Saville, B.P. and T. Institute, Physical Testing Of Textiles. 1999: Woodhead Publishing, Limited.

[23] Huang, J., Thermal parameters for assessing thermal properties of clothing. Journal of Thermal Biology, 2006. 31(6): p. 461-466.

[24] Scott, R.A., Textiles for protection. 2005, New York: Woodhead publishing limited.

[25] Barker, R.L., From fabric hand to thermal comfort: the evolving role of objective measurements in explaining human comfort response to textiles. International Journal of Clothing Science and Technology, 2002. 14(3/4): p. 181-200.
[26] Yoo, S. and R.L. Barker, Comfort properties of heat-resistant protective workwear in varying conditions of physical activity and environment. Part I: Thermophysical and Sensorial Properties of Fabrics. Textile Research Journal, 2005. 75(7): p. 523-530.

[27] SDLATLAS, Moisture Management Tester Operation Manual, in Principle of Operation. 2010, SDL Atlas LTD: Stockport, England.

[28] $\mathrm{Hu}, \mathrm{J}$., et al., Moisture Management Tester: A Method to Characterize Fabric Liquid Moisture Management Properties. Textile Research Journal, 2005. 75(1): p. 57-62.

[29] SDL, INSTRUCTION MANUAL FOR THE M259B SWEATING GUARDED HOT PLATE. 2011, Stockport, England: SDL ATLAS Textile Testing Solutions.

[30] Huang, J., Sweating guarded hot plate test method. Polymer Testing, 2006. 25(5): p. 709-716.

[31] Bivainytè, A. and D. Mikučionienè, Investigation on the air and water vapour permeability of double-layered weft knitted fabrics. FIBRES \& TEXTILES in Eastern Europe, 2011. 19(3): p. 86.

[32] Benisek, L., P.R. Harnett, and M.J. Palin, Influence of Fibre and Fabric Type on Thermophysiological Comfort. Melliand Textilber. Eng., 1987. 68(12): p. 878.

[33] D'Silva, A.P., et al., Concurrent Determination of Absorption and Wickability of Fabrics: A New Test Method. Journal of The Textile Institute, 2000. 91(3): p. 383-396.

[34] Holme, I., Survival 2002. Textile Month, 2002(5): p. 35-37.

[35] Holme, I., Survival 2002: Performance Garments. Textile Horizons, 2002(5/6): p. 7-8.

[36] Li, Y., W. Xu, and K.W. Yeung, Moisture Management of Textiles, U.S. patent, Editor. 2000: US.

[37] SDL, MMT User Manual. School of Fashion and Textile, RMIT University. 2005, England: SDL Atlas, LTD. 